\title{
Smart Learning in the Pacific: Design of New Pedagogical Tools
}

\author{
Bibhya Nand Sharma \\ Faculty of Science, Technology and \\ Environment \\ The University of the South Pacific \\ Suva, Fiji \\ bibhya.sharma@usp.ac.fj \\ Emmenual Reddy \\ Faculty of Science, Technology \& \\ Environment \\ The University of the South Pacific \\ Suva, Fiji \\ emmenual.reddy@usp.ac.fj
}

\author{
Ravneil Nand \\ Faculty of Science, Technology and \\ Environment \\ The University of the South Pacific \\ Suva, Fiji \\ ravneil.nand@usp.ac.fj \\ Swasti Shubha Narayan \\ Faculty of Science, Technology \& \\ Environment \\ The University of the South Pacific \\ Suva, Fiji \\ swasti.narayan@usp.ac.fj
}

\author{
Mohammed Naseem \\ Faculty of Science, Technology and \\ Environment \\ The University of the South Pacific \\ Suva, Fiji \\ mohammed.naseem@usp.ac.fj \\ Karuna Reddy \\ Centre for Survey Research and Methods \\ Australian National University \\ Canberra, Australia \\ karuna.reddy@anu.edu.au
}

\begin{abstract}
Smart learning ecosystems leverage on state-of-theart tools and technologies to help students learn better with Information Communication Technologies (ICT). The ubiquity, innovations and advancements of ICT have transformed pedagogies and approaches to content facilitation and delivery in higher education worldwide, the Pacific region being no exception. The paper essays a number of learning and support tools designed in-house or adopted (or outsourced) recently by a higher education institution in the Pacific contributing to the smart learning ecosystem. The institution has integrated these ICT driven tools to its academic and support programmes, and more recently the in-country science programmes introduced in its member countries. The strengths and challenges from the implementation of these new adaptive tools are highlighted with recommendations to the wider academic populace.
\end{abstract}

Keywords-ICT, Pacific, diagnostic tool, smart learning, higher education

\section{INTRODUCTION}

Information and Communications Technologies (ICT), a strong agent for change, has made its mark in many facets of human life. From the global success of corporate world to the efficient operation of government departments, ICT has provided positive opportunities to enhance business processes in public and private sectors, including Higher Education Institutes (HEI). Incorporating ICT for the enhancement of the education ecosystem is a key priority amongst educationists and HEI. Through the availability of Internet and smart devices, education has been transformed in ways that were previously impossible. ICT has added value to the process of learning by complementing the traditional teaching methodologies [1][2] hence creating smart learning ecosystems.

ICT has transformed pedagogies by making education more student-oriented [3]. It has improved the accessibility of education so that students can benefit from the same quality of education from any location at any time through e-learning. Education that was previously geographically restricted is now possible through different technological mediums such as learning management systems and MOOCs [4]. Advancements in technology has also redefined the role of teachers. The abundance of information online has motivated teachers to make their teaching innovative by designing engaging and interactive online activities and creating instructional materials available online for easy access. Students have access to immense information for their homework and assignments such as e-books, audio, images, and videos [1]-[3].

In recent times, ICTs have been introduced in developed countries creating smart learning platforms and leading to continuing evolution of learning and teaching [1][2]. According to a recent higher education report [5], most of the top $10 \mathrm{big}$ picture themes of educational change focus on technological advancements. However, there is a need for the education systems to be agile enough to promote open content in unique ways. Having benefits through ICT is obvious in HEI but with technological enhancement comes challenges, which need equal consideration as well. Factors such as effective presence of the facilitators, feeling of segregation, lack of student incentives, frequent inclusion of new tools, ICT competencies, and student uncertainties about their learning led to high dropouts [6]-[8].

In HEI, digital literacy has introduced new educational practises to deepen the learning experience of students. According to [9], while digital literacy is essential for HEI there are institutions that have not adequately embraced the concept resulting in digital divide. The challenges brought by digital divide include but not limited to, students' ability to develop technological skills, unwillingness to learn new technology, and over-confidence that impact acquiring relevant digital skills [10] to perform at the same level as others in a program of study. The lack of infrastructure, issues with network connectivity, accessibility and cost of data plans in developing countries are barriers to enhanced ICT driven learning such as mobile and smart learning [11], and in-country programs such as the Science Teachers Accelerated Programme (STAP) designed for Pacific Island Countries [12]. 
Many HEI around the world, including The University of the South Pacific (USP), are investing substantially to harness the potential of ICT in providing quality education equitably to all their students. Being the lead academic institute in the Pacific region, USP has not failed to embrace the ubiquitous technology to provide better services through e-learning, allowing students to access the course notes and required deliverables, submit assignments, raise queries, take part in forums and e-mentoring, as well as check their exam timetable and grades; all possible via ICT [6].

In this paper, the authors will highlight new learning and support tools designed in-house or adopted (or outsourced) recently by The University of the South Pacific contributing to the smart learning ecosystem, with a discussion on the strengths and challenges.

\section{ICT AND HIGHER EDUCATION}

A wide spectrum of ICT tools and technologies have been embraced in the 21 st century to facilitate information sharing and communication [3]. The use of ICT has become indispensable in contributing to the progress in all areas of our lives including education, health, housing, business, and financial services [13]. The increasing use of effective and reliable technologies in higher education has fundamentally strengthened the teaching and learning processes [1]. ICT has infiltrated the areas of course material development, content delivery and dissemination, communication between teachers and students, and research in universities [2].

\section{A. Current Trends}

Digital technologies that are currently making its mark in the education sector globally include:

- Massive Open Online Course (MOOC),

- Open Educational Resources (OER),

- Web 2.0 tools including blogs, wikis, social networking and Google Apps, and

- Mobile learning (m-learning).

\section{B. Future Trends}

ICTs will continue to play the role of a catalyst in the educational reform. The future of education will experience an increase in the use of digital technologies to improve the services provided by academic institutes. The potential of mobile devices such as smart phones and Tablet PCs will be further explored by educationists in an attempt to provide learners with a personalised learning experience. ICTs will further help curb and curtail student cheating (including contract cheating) and plagiarism. In addition, learning analytics will also be better utilised in order to assist education providers to make better and informed decisions. Although cloud computing has been introduced quite a long ago, the extent to which it can impact teaching and learning still needs to be explored. Cloud computing provides a panacea to the problems associated with hardware and software management. With this obstacle out of the way, organisations will now shift their focus on leveraging the use of ICT for their primary process, that is, teaching and learning.

\section{SMART LEARNING}

Educational reforms are inevitable due to the growing popularity of technological devices such as mobile phones and Tablet PCs amongst our students. HEI attempt to incorporate innovation through the use of mobile devices and smart platforms to provide learners with a learning environment in which they are able to better comprehend and organize knowledge, solve problems and make inferences based on what they have learnt [14]. Smart technology has an impact in transforming teaching and learning from content-centred curricula to competency-based curricula, essentially a move from teacher-centred to student-centred learning [15] and creating smart learning ecosystems. Smart learning can be regarded as a new learning paradigm that uses technologysupported environments to enable effective, efficient, engaging, and personalized and differentiated learning [16]. Smart learning provides easy access to learning resources, enhances interaction between learners and instructors', and provides ubiquitous learning to self-directed learners [14].

\section{A Case Study: The University of the South Pacific}

This section highlights support tools that have been designed and implemented at The University of the South Pacific as smart learning tools to encompass learning and teaching at HEI, and help create a smart learning ecosystem. Fig. 1 illustrates the tools introduced at USP together with the ones that are included in the future plans.

\section{A. Background}

The University of the South Pacific owned by 12 member countries - Cook Islands, Fiji Islands, Kiribati, Marshall Islands, Nauru, Niue, Samoa, Solomon Islands, Tokelau, Tonga, Tuvalu and Vanuatu has been in operation since 1968 and is one of the three regional universities in the world. It provides higher education to more than 29,000 students [17] studying from 14 campuses and 10 centres spread in an area of 30 million square kilometres in the Pacific Ocean where a significant portion of the spread include terrestrial and marine biodiversity [18]. The Laucala Campus situated in Suva (Fiji Islands) is designated as the main campus, hence seen to be the hub of the university's administrative and academic operations [19].

However, with the geographical spread of the member countries, it becomes a huge challenge for USP to deliver premium quality education and support services equitably to students based in different campuses and centres. For the university, it is not only a matter of availability and accessibility to education but also an attempt to instil specific graduate attributes and create global citizens [19]. The USP has its own telecommunication system known as USPNet, which uses satellite and links all the regional campuses through the $\mathrm{C}$ Band (see Fig. 2). In addition, the university uses Intelsat to link to the $\mathrm{Ku}$ Band sites that it has placed in several locations that do not have good access through the satellite allowing for scalability of intranet services [20]. 


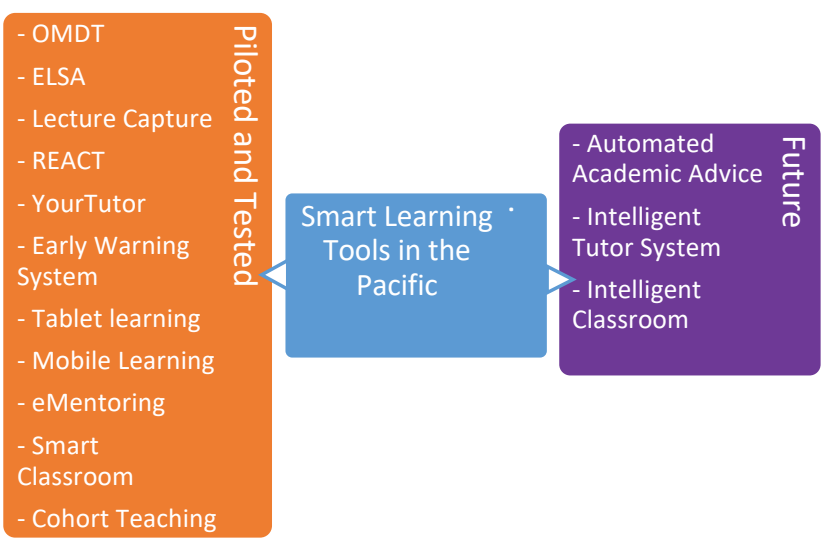

Fig. 1. Smart learning Tools in the Pacific.

\section{B. Virtual Classroom - REACT Services}

The University of the South Pacific utilizes the REACT (Remote Education and Conferencing Tool) software program for the delivery of interactive distance learning to students based in the regional campuses and centers. REACT provides 'real time' collaborative classroom experience enabling the teacher and the students to interact using rich multimedia with audio and video [21]. The service runs from designated venues available from all campuses of the university [4]. The programme is given high priority on the network to prevent lag in audio and video. Furthermore, each campus has IT trained staff to troubleshoot any issues that may arise at the user end.

\section{Mobile Learning}

The usage of mobile devices for m-learning in Pacific is trending now, being the most popular in higher education institutes [22][23]. While the regional governments in collaboration with NGOs, donor agencies and others are making way for the usage of mobile devices to be integrated to education, there is little evidence or documentation on what the students want and how they perceive this innovation. A recent survey in the Pacific has found that most users in the Pacific opt for smartphones [24]. Fig. 3 shows the general decrease in $2 \mathrm{G}$ mobile phones used by students and increase in smart phone ownership.

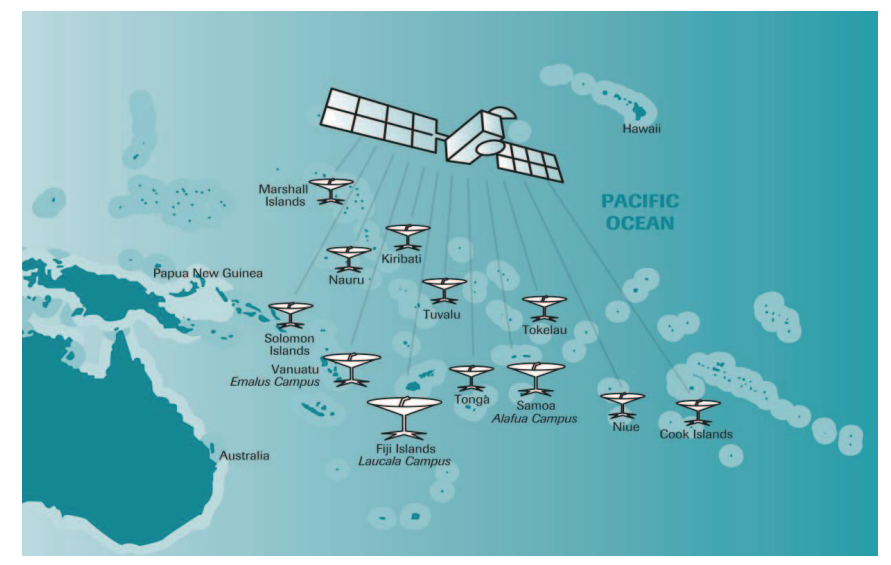

Fig. 2. USP member countries connected throughout the Pacific region using the USPNet. Adopted from USP strategic plan 2013-2018. [25]
Mobile learning is any form of learning that takes place with the use of mobile technologies and happens when the learner is not at a fixed, predetermined location [26][27]. These technologies provide increased mobility and access to learning to the user, examples include mobile phones, notebooks, tablets laptops, PDAs etc. The web and mobile based services and applications, especially ones integrated with games such as edutainment fancy the learners. The mobiles devices are becoming more powerful and are able to support many types of applications and services, invariably promoting studentcentered learning, nourishing the student agency, and strategically designed to mobilize societal changes [22].

A number of mobile applications have been developed inhouse at USP which include the recent USP Mobile App with 628 active users, USP Campus Map App with 355 active users, In-country Science App with 69 active users and Events App with 40 users. Offline notifications can be sent to the application users, a feature now replacing the SMS notification feature previously used at the university.

\section{Online Mathematics Diagnostic Tool (OMDT)}

A general decrease in core mathematical skills has been observed from mathematics diagnostics tests conducted by higher education institutions in Europe as reported by [28], and student performance at USP highlight a similar decline. The students at the university come from various regional and international countries with different mathematics curricula, coverage and experience, and therefore have varying levels of mathematics knowledge. To curtail this issue, the Online Mathematics Diagnostic Tool (OMDT), which is an online numeracy support tool was developed. The OMDT is an intelligent testing system that diagnoses student's knowledge in different areas of mathematics. A pass in all the module takes the students to the questionnaire and certification tool while a fail in the module(s) directs the students to the modules remedial, following which students can re-attempt the online test. Three versions of OMDT have been designed with different difficulty levels, OMDT1 for the science students, OMDT2 for the non-science students and OMDT3 for the general public. The tool is developed in the Moodle platform and is accessed by students using their student credentials and also has social authentication feature for the general public.

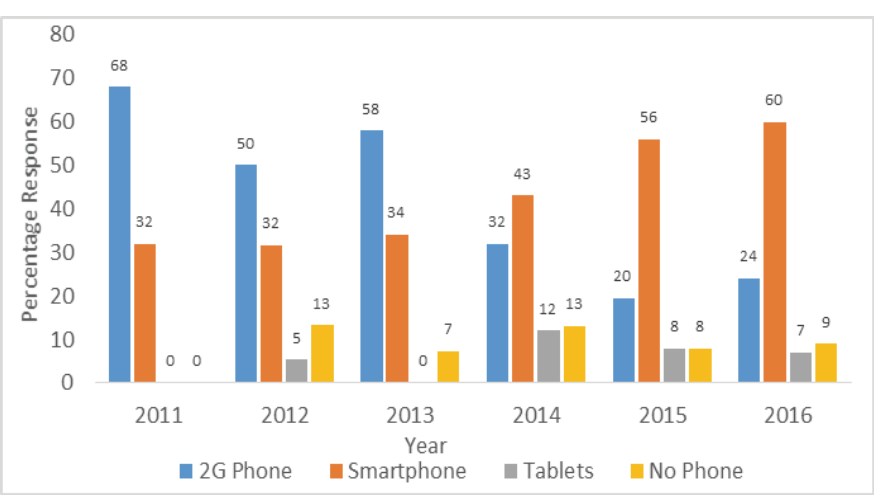

Fig. 3. The types of mobile devices owned by The University of the South Pacific students from 2011-2016. 
Data from OMDT shows varying percentage pass rates for the modules indicating different levels of understanding of the concepts. Fig. 4 shows that OMDT1 offered in 2017 had highest percentage pass for the integration module while lowest percentage pass was for the probability and statistics module. On the other hand, the campus data shows that lowest percentage pass at Alafua Campus was for functions and differentiation modules, Kiribati Campus had lowest percentage pass for probability and statistics and Vanuatu Campus had lowest percentage pass for differentiation and integration. Thus, this tool is important to identify the weaknesses of the students and provide subsequent online remedial to bring them up to par with the expected mathematics knowledge level required for degree programs at USP.

\section{E. Early Warning System}

An early warning system (EWS) is utilized by education institutes to track their student activity and performance via the learning management systems [29]. An EWS plug-in for Moodle was designed by USP to predict the students' performance in online courses and courses with high percentage of online activities at the university. The alert tool was able to capture student login details, online engagement on the resource and activities and completion of online assessments. The Moodle data was analysed using the regression model to determine any correlation between student's online behaviour and their performance. The students' average logins to the course per week and average completion rates of activities were used to predict their performance. The accuracy of the model was $60.8 \%$, indicating that EWS can be an effective tool to track and measure student progression. This tool is especially helpful to identify the at risk students early so that appropriate interventions programs can be put in place [30][31]. The EWS dashboard is embedded in the students' course Moodle page (shown in Fig. 5) which allows students to keep track of their performance as well.

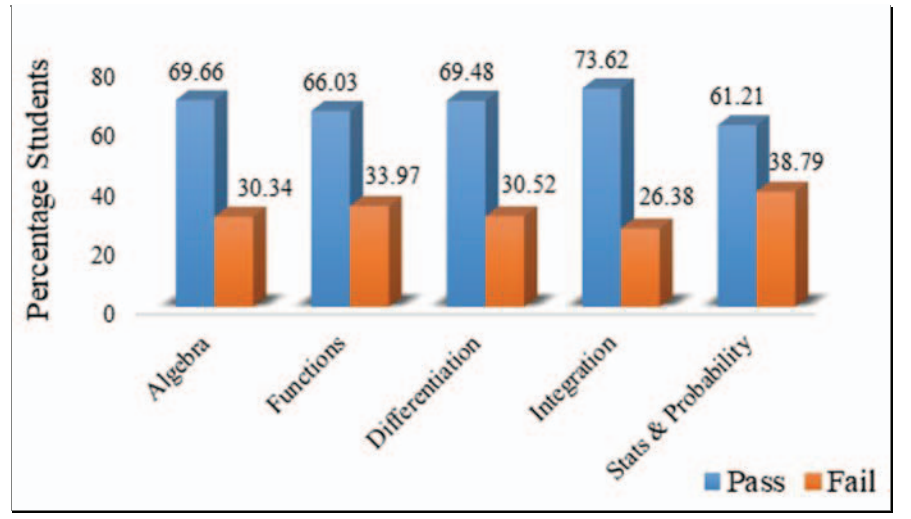

Fig. 4. Showing percentage of students who passed and students who failed the OMDT1 modules in 2017.

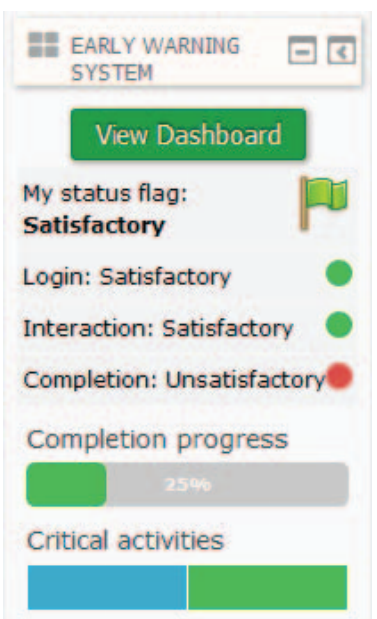

Fig. 5. An example of a EWS Dashboard.

\section{F. Tablet Learning}

In 2017, every freshmen on full-time undergraduate studies was provided the opportunity to receive an Android tablet each through the initiative of the university's vice-chancellor. This came about after the success of the pilot programme in the region carried out in 2014 for different cohorts of students in selected campuses [12]. The tablets have also been provided to students who are enrolled in the In-country Science Programmes in the member countries (Samoa, Tonga (Fig. 6) and Vanuatu). The tablets are provided free of charge and students sign a contract to take care of the tablet. The project is opening doors for smart learning in the Pacific where the students do not have to rely on the desktop computers to finish assignments and tasks of any courses [32][33].

This initiative has come keeping in mind the recent and future impacts of digital transformation of societies on universities [33]. The university has re-calibrated its information and communication infrastructure and services for a better learning and teaching experience, two priority areas captured in its 2013-2018 Strategic Plan [25].

\section{Student Testimonials:}

- "The Tablet learning project 2017 has been really helpful for me this semester. The tablet is light and portable making it ideal to use at all times. I am so thankful for being part of this project and I would recommend it to anyone else."

- "It is very useful in a sense that I don't have to carry my books in school. I just carry the tablet with me to school, and as I get free time I use it to read the lesson notes."

- "As a working student, I am glad that I can take the tablet home and use the tablet offline to read the course notes, attempt quizzes and submit my assessments." 


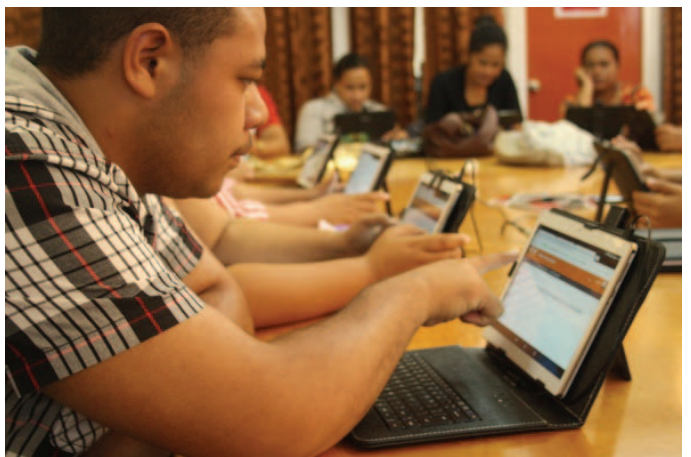

Fig. 6. Tongan students using new tablets.

\section{G. E-Mentoring}

The use of e-mentoring for higher education is not a new concept for many universities but affording it for distant and flexible learning students in universities with low bandwidth, is still a major hurdle [34][35]. The USP ventured into the ementoring project through its science faculty with the existing infrastructure by creating a basic virtual classroom using open source software BigBlueButton (BBB) [36] in selected campuses (Fig. 7) in 2014. The software enables students/mentors to share documents, webcams, chats, audio and their desktop. It also has the feature to record the sessions which are made available to the students via Moodle [34][35].

The main objective for introducing this tool in the university is to afford a shared and supportive environment of a real-world mentoring session for mature, working as well as disabled students in the regional campuses, who do not have the luxury of being at the campus all day long to attend classes or get face-to-face mentoring/tutoring support.

\section{H. Cohort based Learning}

The term cohort refers to a group of learners who begin coursework together, progress through academic program requirements and complete the program as a group. Cohort models have gained popularity as they promote collaborative learning with a supportive group environment [37]. The Science Teachers Accelerated Programme (STAP) is a new cohort-taught pedagogical model designed by the science faculty at USP to address the issue of underqualified science teachers in the Pacific. The STAP model is an intensive 2 year model to upgrade the existing qualifications of underqualified teachers teaching science in secondary schools. The programme has mixed delivery modes and leverages heavily on ICT tools and technologies, including tablets and virtual classrooms. The first STAP was successful with $86.4 \%$ students in the cohort graduating with a Bachelor of Science degree. The reader is referred to [12] for a detailed account of STAP. Currently, the In-country Science Programme which is designed using the STAP model is run in Samoa (55 teachers), Tonga (45 teachers and 60 freshmen), and Vanuatu (90 teachers and 10 freshmen) where the science teachers have been provided scholarships by their governments.
Fig. 7. The university campuses where e-mentoring is fully supported.

\section{English Learning Skills Assessment (ELSA) online}

Students enrolling in universities with non-English speaking backgrounds face challenges with their studies [38] showing the need for diagnostic tools for the language. The English Language Skills Assessment (ELSA) tool designed by USP in 2017 tests the English proficiency skills (listening, reading and writing) and provides appropriate remediation for its entry-level students. Completion of ELSA is a prerequisite for registration into the second year courses. A major challenge during the development phase was to identify the best platform to run the test for the three skills. Plagiarism was another concern of the team therefore three different sets of each skill was developed and these are randomly generated for each user. The online testing tool enables students to receive feedback instantly compared to the previous testing system that took a few weeks. Furthermore, the students who do not meet the required standards are automatically enrolled in the English Language support exercises course on Moodle and are required to accomplish $80 \%$ success in the exercises.

\section{J. Lecture Capture System}

The lecture capture system is another exciting technology gaining attention from higher education institutions across the globe. Video lecture capturing systems address the problem of attendance to class, and student retention [39]. The system allows for self-paced review of the lectures and is beneficial for students who are not able to attend the class and those who wish to review the contents for reinforcements.

The Lecture Capture Project was launched in 2017 at USP and has its large lecture theatres equipped with lecture capture software. The recorded lectures include the audio, the lecture slides that are projected on the screen and lecturers' annotations in class. The system is automated to start recording when the lecture commences till the end of the lecture. The recording is subsequently extracted to the respective course shells on Moodle as shown in Fig. 8 [40].

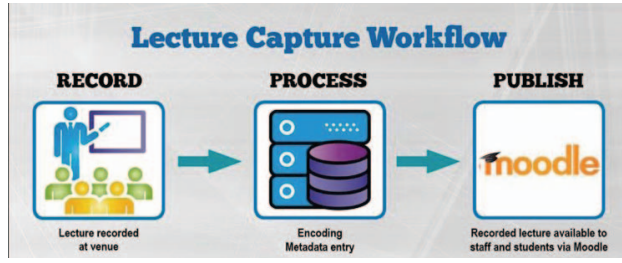

Fig. 8. Lecture Capture workflow [40]. 
The challenges encountered in the initial phases of the project included low audio quality, intermittent recording transfers and power outage. Academic staff training and provisioning of instructional guides have helped curb the audio quality issue while issues related to the system have been addressed by strengthening the system with assistance from the vendor. The system has positive feedback from the students based in the region with the only issue of difficulty to download the videos in areas of poor network connection. Students with network connection issues are encouraged to download the videos from within the university network.

\section{Challenges in Adopting Smart Learning Tools in the PACIFIC}

The emergence of new technologies has made it vital for HEI to implement ICT tools and smart learning ecosystems to cater for the varying types of learning needs [6][41][42]. While the benefits of shifting from traditional to smart learning systems are obvious, there are often challenges that need to be addressed prior to the shift.

In the Pacific region, the countries and territories are spread over 33 million square kilometers of the Pacific Ocean. These countries and territories face the problems of smallness and geographic isolation that have made delivery of equitable high quality education by HEI a big challenge. Some of the underlying issues include, but not limited to, equitable student support, timely delivery of course and programme materials, ICT infrastructure, high student enrolments required in order to mount programs in local campuses, travel logistics, decision making and governance, and a lack of local teaching and support staff [18][12].

Additionally, the International Education Advisory Board (IEAB) states that the ubiquitous use of technology is mounting enormously and the rate at which ICT infiltrates the learning environment is immense. Digital literacy has evolved through the years and is invariably utilized to explain the ability to use technological skills, such as internet and computer skills in different aspects of life [43]. Digital literacy in higher education has introduced new educational methodologies to enrich the learning experience of students. Murray \& Pérez [9] agree that digital literacy is an essentially required skill in this modern competitive environment; nevertheless, there are higher educational institutions that have not adequately embraced digital literacy, thus creating a digital divide. In the Pacific, high school students who enter universities may have hardly or never used any smart learning tools. With the low and varying digital literacies in the Pacific, implementing new learning tools become a problem, and therefore focus has to be on baseline studies to capture students' attitude, perception and competencies of new tools and technologies. Subsequently, using the analytics to facilitate awareness, training and reformed curricula.

According to [11], lack of infrastructure is one of the barriers to the implementation of mobile learning system in developing countries. To overcome this constraint, USP is now providing free tablet devices with computational capabilities to each freshman enrolled in full-time undergraduate studies [44]. In addition, the university is also providing free $\mathrm{Wi}-\mathrm{Fi}$ hotspots in all its campuses so that students can access internet on their devices [6][12][44]. To ensure seamless use of smart learning tools the Pacific island countries are moving towards investing in fibre optic cables that enable faster connectivity. In the last ten years, apart from Fiji a number of other Pacific islands including Tonga, Samoa, Vanuatu and Marshall Islands have been connected to the high speed fibre optic cable [45][46]. The recent Fiji government budget revealed certain geographic locations to be free high-speed Wi-Fi hotspots [47].

Recently an improved access to technology in the Pacific such as mobile and broadband [23] has led to multiple social and economic benefits such as entrepreneurship, innovation, higher quality of services and products, and projecting a more supportable and equitable higher education for the Pacific. The USP has reformed facilitation of its programs by incorporating ICT via smart learning tools to improve its flexible and distance learning processes, and providing interactive, engaging and equitable high quality learning to its learners [6]. Furthermore, [32] and [20] found that the use of m-learning in USP is seen to be one of the best tools that has enabled the university to provide a more collaborative, transformative and reflective learning over the recent years.

The smart learning tools in the Pacific have benefited a lot of students in HEI in the Pacific but it has its share of challenges as well. From the start of REACT sessions at USP to the automation of ELSA, a number of significant changes have been made. Where internet and lack of infrastructure made the delivery of services challenging, more innovative ideas were developed. To achieve a milestone in the HEI in the Pacific, more proactive approaches are needed to be taken instead of just rolling a service or tool. As smart ICT tools were introduced, more enhancements were done to the infrastructure and interconnectivity. In response to rapid technology induced evolution of HEI teaching and learning processes, the smart learning tools discussed in section IV were implemented at the USP and are being continuously modified to enhance students' learning experience. The REACT services at the USP started with one REACT venue and was later expanded to three venues and dedicated lines were given for the services. The REACT, ementoring, lecture capture and cohort teaching effectively bridge the learning differences associated with the geographical spread and provide equitable learning experience to the distant learners at their home turf. The OMDT and ELSA online provide the necessary diagnosis and remedial for the numeracy and literacy skills respectively for the first year students joining the university while the tablet learning project boosts their access to the much needed notes, information and services for their courses. The mobile learning, e-mentoring, and lecture capture tools on the other hand provided the technology enabled learning to all university student irrespective of the delivery modes or level of study. While these existing tools are providing the desired services and support, the next phase is to upgrade the existing tools to create smart learning environments and design smart learning tools par with the advances in education technologies.

\section{CONClusion AND Future DiRECTION}

ICT trends in education are still evolving and transforming education with an escalating pace and demand. 
The potentials of mobile devices will be further explored by educationists in an attempt to provide learners with personalized learning experience and differentiated instructions. The HEI in the Pacific have embraced digital technologies and are working in creating smart learning ecosystems for their students. This will not be easy when one considers the constraints and restrictions the Pacific countries face, but the movement is certainly in the right direction. New tools, programs and learning environments are been designed in consideration of the challenges and opportunities available in the Pacific. Tailored cohort-based programs such as STAP and support tools such as e-mentoring, m-learning, OMDT, ELSA are helping provide equitable premium quality higher education and student support to the wider populace in the Pacific. These also provide essential components to the smart learning ecosystem of HEI. However, while this re-engineering is taking place, there is a sincere need for training of teachers, and students. There is a need for wider consultation and collaboration so that the government ministries and donor agencies know of the common areas of investment and improvement.

Future direction of HEI is towards fully functional smart learning ecosystems, which can also include automated academic advising system for educationists and students, intelligent tutoring system and intelligent classrooms.

\section{REFERENCES}

[1] Telkom. (2015). Technology in Education [Online]. Available: https://secure.telkom.co.za/today/media/downloads/Education.pdf

[2] S. Talebian, H. Mohammadi and A. Rezvanfar, "Information and Communication Technology (ICT) in Higher Education: Advantages, Disadvantages, Conveniences and Limitations of applying e-learning to agricultural students in Iran," Procedia-Social and Behavioral Sci., vol. 152, pp. 300-305, 2014.

[3] J. Anderson. (2010). ICT Transforming Education: A Regional Guide [Online]. unesdoc.unesco.org/images/0018/001892/189216e.pdf

Available:

[4] Commonwealth of Learning. (2014) COL Review of Flexible Learning at the University of the South Pacific [Online]. Available: http://hdl.handle.net/11599/1675

[5] A. S. Becker et al, "The NMC Horizon Report: 2017 Higher Education Edition," The New Media Consortium, Austin, TX, 2017.

[6] B. Sharma et al, "A Mobile Learning Journey in Pacific Education," in Mobile Learning in Higher Educ. in the Asia-Pacific Region, vol. 40, A. Murphy, H. Farley, L. E. Dyson, H. Jones, Ed. Singapore: Springer, 2016, pp. 581-605.

[7] J. Haag, "From eLearning to mLearning: The Effectiveness of Mobile Course Delivery," in Interservice/Industry Training, Simulation and Educ. Conf., Orlando, FL, 2011, pp. 1-13.

[8] S. Rosenblit and B. Gros, "E-Learning: Confusing Terminology, Research Gaps and Inherent Challenges," Int. J. of eLearning and Distance Educ., vol. 25, no. 1, pp. 1-8, 2011.

[9] M. C. Murray and J. Pérez, "Unraveling the digital literacy paradox: How higher education fails at the fourth literacy," Issues in Informing Sci. and Inform. Technology, vol. 11, pp. 85-100, 2014.

[10] L. Jeffrey et al, "Developing digital information literacy in Higher Education: Obstacles and Supports," J. of Inform. Technology Educ.: Research, vol. 10, no. 1, pp. 383-413, 2011.

[11] S. A. Shonola and M. S. Joy, "Barriers to m-Learning in Higher Education Institutions in Nigeria," in Proc. of Int. Conf. of Educ., Research and Innovation, Seville, Spain, 2014.
[12] B. Sharma et al, "Science teachers accelerated programme model: a joint partnership in the Pacific region," Asia-Pacific J. of Teacher Educ., vol. 46, no. 1, pp. 38-60, 2018.

[13] H. K. Sharma, "Role of ICT in Improving the Excellence of Education," Int. J. on Comp. Sci. and Eng. (IJCSE), vol. 7, no. 8, pp. 78-81, 2015.

[14] G.-J. Hwang, "Definition, framework and research issues of smart learning environments - a context-aware ubiquitous learning perspective," Smart Learning Environments, vol. 1, no. 1, pp. 1-14, 2014.

[15] R. Oliver, "The role of ICT in Higher Education for the 21st century: ICT as a change agent for education," Proc. of the Higher Education for the 21st Century Conf., Curtin, 2003.

[16] M. N. Giannakos, S. G. Demetrios and Ł. Kidziński, "Introduction to smart learning analytics: Foundations and Developments in video-based learning," Smart Learning Environments, vol. 3, no. 12, pp. 1-9, 2016.

[17] R. Chandra. (2017). Welcome to USP [Online]. Available: http://www.usp.ac.fj/index.php?id=3765

[18] P. B. Corcoran and K. K. Chacko, "The Pacific way: Sustainability in Higher Education in the South Pacific Island nations," J. of Sustainability in Higher Educ., vol. 11, no. 2, pp. 130-140, 2010.

[19] B. Sharma and A. Jokhan, "Distance and Flexible Learning at The University of the South Pacific," in Accessible Elements: Teaching Science Online and at a Distance, Edmonton, Alberta, Canada, Athabasca University, 2010, pp. 235-246.

[20] B. Sharma et al, "Use of Short Message Service for Learning and Student Support in the Pacific Region," in Handbook of mobile teaching and learning, in Y. Zhang, Ed. Berlin Heidelberg: Springer, 2015, pp. 199-220.

[21] B. Devlin, "The REACT software program: a promising way to surmount the technical and educational challenges associated with interactive distance learning in Australia," in ED-MEDIA 2008-World Conf. on Educ. Multimedia, Hypermedia \& Telecommun., Vienna, Austria, 2008.

[22] J. Keengwe and M. Bhargava, "Mobile learning and integration of mobile technologies in education," Educ. and Inform. Technologies, vol. 19, no. 4, pp. 737-746, 2014.

[23] International Telecommunication Union. (2016), The State of broadband 2015 [Online]. Available: https://www.itu.int/pub/S-POLBROADBAND.13-2015

[24] E. Reddy, P. Reddy, B. Sharma, K. Reddy and M. Khan, "Student Readiness and Perception to the Use of Smart Phones for Higher Education in the Pacific," in 3rd Asia-Pacific World Congr. on Comput. Sci. and Eng., Nadi, Fiji, 2016. pp. 258-264

[25] The University of the South Pacific. (2013), Strategic Plan 2013-2018 [Online]. Available: https://www.usp.ac.fj/strategicplan2013-2018

[26] C. O'Malley, G. Vavoula, J. P. Glew, J. Taylor and M. Sharples. (2005), Guidelines for Learning/Teaching/Tutoring in a Mobile Environment [Online]. Available: https:/hal.archives-ouvertes.fr/hal00696244/document

[27] J. Traxler and A. Kukulska-Hulme, "Evaluating Mobile Learning: Reflections on Current Practice," in mLearn 2005: Mobile technology: The future of learning in your hands, Cape Town, South Africa, 2005.

[28] M. Carr et al, "Mathematics diagnostic testing in Engineering: an International comparison between Ireland and Portugal," European J. of Eng. Educ., vol. 40, no. 5, pp. 546-556, 2015.

[29] Y.-H. Hu, C.-L. Lo and S.-P. Shih, "Developing early warning systems to predict students' online learning performance," Comput. in Human Behavior, vol. 36, pp. 469-478, 2014.

[30] V. Singh, B. Sharma, A. Jokhan and S. Singh, "Early warning system: Innovative student monitoring in an eLearning environment," in 12 th Pacific Science Inter-Congress, Suva, Fiji, 2013.

[31] A. Jokhan, B. Sharma and S. Singh, "Early warning system as a predictor for student performance in higher education blended courses," Stud. Higher Educ., 2018.

[32] P. Reddy and B. Sharma, "Effectiveness of Tablet Learning in online courses at the University of the South Pacific," in 2nd Asia-Pacific World Congr. on Comput. Sci. and Eng., Nadi, Fiji, 2015. 
[33] S. C. Li, J. W. C. Pow, E. M. L. Wong and A. C. W. Fung, "Empowering student learning through Tablet PCs: A case study," Educ. and Inform. Technologies, vol. 15, no. 3, pp. 171-180, 2010.

[34] C. A. Kasprisin, P. B. Single, R. M. Single and C. B. Muller, "Building a better bridge: Testing e-training to improve e-mentoring programmes in Higher Education," Mentoring and Tutoring, vol. 11, no. 1, pp. 67-78, 2003.

[35] L. L. Bierema and S. B. Merriam, "E-mentoring: Using computer mediated communication to enhance the mentoring process," Innovative Higher Educ., vol. 26, no. 3, pp. 211-227, 2002.

[36] D. Bhartu and J. Yusuf, "Technology-Enabled environments for Flexible learning: A Case Study at The University of the South Pacific," in PanCommonwealth Forum 8 (PCF8), Kuala Lumpur, Malaysia, 2016.

[37] C. J. McPhail, M. Robinson and H. Scott, "The cohort leadership development model: Student perspectives," Community College J. of Research and Practice, vol. 32, no. 4-6, pp. 362-374, 2008.

[38] C. Lydster and S. Brown, "The value of Post-Entry Language Assessment (PELA): Outcomes from a first semester undergraduate subject," J. of Academic Language and Learning, vol. 11, no. 1, pp. A39-A57, 2017.

[39] N. Toppin, "Video lecture capture (VLC) system: A comparison of student versus faculty perceptions," Educ. and Inform. Technologies, vol. 16, no. 4, pp. 383-393, 2011.

[40] The University of the South Pacific. (2017). Lecture Capture Project [Online]. Available: https://www.usp.ac.fj/index.php?id=19188.
[41] R. Geer. (2012) Technology changing teaching [Online]. Available: http://www.lutheran.edu.au/assets/Uploads/pr/web/Publications\%20and \%20policies/Online\%20publications/SchooLink/SCHOOLINKVol181.p df

[42] H. Lavery. (2012, June 12) Why it matters to Higher Education [Online] Available: http://www.educause.edu/ero/article/breaking-down-barrierstablet-technology-teaching

[43] M. Sáinz, C. Castaño and M. Artal. (2008). Review of the concept of digital literacy and its implications on the study of the gender digital $\begin{array}{lll}\text { divide } \quad \text { [Online]. Available: } & \end{array}$ http://openaccess.uoc.edu/webapps/o2/bitstream/10609/1283/3/sainz_cas tano_artal.pdf

[44] The University of the South Pacific. (2017, Jan. 19). USP students to be issued tablets for learning [Online]. Available: http://www.usp.ac.fj/news/story.php?id=2316\#.WJ-80st2jwo

[45] M. Minges and C. Stork, "Economic and Social Impact of ICT in the Pacific," Pacific Region Infrastructure Facility, Sydney, Australia, Rep. 2015, June 2015.

[46] F. Naigulevu. (2018, May 29) Savusavu cable system to boost northern internet connectivity [Online]. Available: http://www.fijitimes.com.fj/savusavu-cable-system-to-boost-northerninternet-connectivity/

[47] S. Devi. (2018, June 28). 2018 Budget: Allocation to set up high-speed internet hotspots [Online]. Available: http://www.fijitimes.com/2018-19budget-allocation-to-set-up-high-speed-internet-hotspots/ 